\title{
Role of adjuvant cisplatin-based chemotherapy following radical cystectomy in locally advanced muscle-invasive bladder cancer: Systematic review and meta-analysis of randomized trials
}

\author{
Do Kyung Kim ${ }^{1}$, Joo Yong Lee ${ }^{2}$, Jae Hung Jung ${ }^{3}$, Yoon Soo Hah ${ }^{1}$, Kang Su Cho ${ }^{1}$ \\ 'Department of Urology, Gangnam Severance Hospital, Urological Science Institute, Yonsei University College of Medicine, Seoul, ${ }^{2}$ Department of Urology, Severance \\ Hospital, Urological Science Institute, Yonsei University College of Medicine, Seoul, ${ }^{3}$ Department of Urology, Institute of Evidence Based Medicine, Yonsei University Wonju \\ College of Medicine, Wonju, Korea
}

Purpose: We purposed to assess the effects of adjuvant chemotherapy $(\mathrm{ACH})$ on survival outcomes in patients with locally advanced muscle-invasive bladder cancer (MIBC) who are treated with radical cystectomy (RC).

Materials and Methods: Literature search was conducted in PubMed, Embase, and Cochrane library databases for all articles that were published until February 2018. Systematic review and meta-analysis were performed by pooling the randomized controlled trials (RCTs) that compared patients with locally advanced MIBC who received ACH after RC to those who underwent cystectomy alone. Endpoints were progression free survival (PFS) and overall survival (OS).

Results: Four RCTs with a total of 490 patients were selected for the analysis. These four trials included patients with locally advanced MIBC. Pooled HRs for PFS and OS across the studies were 0.48 (95\% confidence interval $[\mathrm{Cl}], 0.39-0.60 ; \mathrm{p}<0.00001)$ and $0.63(95 \% \mathrm{Cl}, 0.48-0.83 ; \mathrm{p}=0.0009)$, respectively. Absolute increases in PFS and OS for locally advanced MIBC were $17 \%$ and $10 \%$, respectively (i.e., equivalent to numbers needed to treat of 5.9 and 10 ).

Conclusions: ACH following RC may improve the survival outcomes of locally advanced MIBC patients. Beneficial effect of ACH might be more marked in patients with locally advanced MIBC when comparing the previously reported meta-analysis with all MIBC patients.

Keywords: Drug therapy; Meta-analysis; Randomized controlled trial; Systematic review; Urinary bladder neoplasms

This is an Open Access article distributed under the terms of the Creative Commons Attribution Non-Commercial License (http://creativecommons.org/licenses/by-nc/4.0) which permits unrestricted non-commercial use, distribution, and reproduction in any medium, provided the original work is properly cited.

\section{INTRODUCTION}

Radical cystectomy (RC) is the standard surgical therapy for patients with muscle-invasive bladder cancer (MIBC)
[1,2]. In patients who undergo RC only, 5-year survival rate for bladder cancer can be up to $80 \%$ for lymph nodenegative and organ-limited disease. Survival rate decreases to $40 \%$ in patients with extravesical extension of bladder

Received: 8 November, 2018 • Accepted: 3 January, 2019

Corresponding Author: Kang Su Cho

Department of Urology, Gangnam Severance Hospital, Yonsei University College of Medicine, 211 Eonju-ro, Gangnam-gu, Seoul 06273, Korea

TEL: +82-2-2019-3471, FAX: +82-2-3462-8887, E-mail: kscho99@yuhs.ac

ORCID: https://orcid.org/0000-0002-3500-8833 
cancer, and it can decrease to $15 \%$ to $35 \%$ if lymph node metastases are present $[1,3,4]$. The primary cause of poor survival rates in patients with locally advanced MIBC may be systemic occult micrometastatic disease present at the time of RC; preoperative imaging studies cannot detect these micrometastases [5]. These findings suggest that extended use of neoadjuvant or adjuvant systemic chemotherapies that eradicate micrometastatic disease should be considered in most patients with locally advanced MIBC, as RC alone may not be effective for disease management [6].

Level 1 evidence demonstrating a survival benefit recommended neoadjuvant cisplatin-based chemotherapy $[7,8]$. However, the use of neoadjuvant chemotherapy (NAC) is low for various reasons, and clinicians must frequently decide whether to recommend adjuvant chemotherapy (ACH) for moderate-to-high-risk patients who have not received NAC [9-11]. ACH following local treatment has resulted in increases in survival rates of patients with solid tumors [12]. Although randomized clinical trials (RCTs) investigating the effect of ACH after RC in patients with MIBC have been performed [13-18], the effects of $\mathrm{ACH}$ for management of MIBC remains controversial [7]. There have been several meta-analysis evaluating the effects of ACH on MIBC patients [6,8,9], but no study has evaluated the effects of ACH on locally advanced MIBC. Moreover, MIBC reflects very broad disease status, and locally advanced MIBC (pT3+ and/or $\mathrm{pN}+$ ) is known to exhibit much poorer prognosis than localized MIBC (pT2pN0). For these reasons, we aimed to examine the effects of $\mathrm{ACH}$ on improvement of survival outcomes in patients with locally advanced MIBC following $\mathrm{RC}$.

\section{MATERIALS AND METHODS}

\section{Search strategy}

We performed computerized bibliographic search of PubMed/MEDLINE, Embase, and Cochrane library databases in February 2018. We used search terms, such as 'urinary,' 'bladder,' 'carcinoma,' 'cancer,' 'chemotherapy,' 'adjuvant,' and relevant variants. Conference abstracts were excluded even if they met the eligibility criteria. In the current study, we only included trials that were published in English. The search included 1,575 articles. Two authors (DKK and YSH) independently reviewed the titles and abstracts based on the inclusion criteria, and reviewed the identified articles.

\section{Trial inclusion criteria}

The eligibility of a study was evaluated with consi- deration of the participants, interventions, comparators, outcomes, and study design (PICOS) approach and the Preferred Reporting Items for Systematic Reviews and Meta-Analyses (PRISMA) guidelines [19]. We defined study population and intervention as patients with locally advanced $\mathrm{MIBC}$ who underwent $\mathrm{RC}$ and $\mathrm{ACH}$, respectively. Comparator was defined as $\mathrm{RC}$ alone. The outcomes measured were progression-free survival (PFS) and overall survival (OS) rates. The following inclusion criteria were used: (1) RCT; (2) not animal research; (3) patients with locally advanced MIBC who underwent RC; (4) ACH; (5) values reported for the PFS and OS outcomes; and (6) availability of Kaplan-Meier/uni- or multi-variate Cox proportional hazard model results to estimate hazard ratios (HRs) and 95\% confidence intervals (CIs).

\section{Data extraction}

Two authors (DKK and YSH) independently reviewed included articles and extracted the data for each trial. Data were extracted at the trial level. Any discord of extracted data between two authors was resolved through consensus. Extracted data included details on study design, inclusion and exclusion criteria, randomization, participant demographic and oncologic characteristics, treatment characteristics (regimen, dosage, planned cycles of $\mathrm{ACH}$, and median follow-up period), outcomes measured (PFS and OS), and results (numbers of events, HRs, 95\% CIs, and p-values).

The primary endpoint was PFS; progression was defined as distant metastasis or local recurrence at the surgical site or local lymph node after $\mathrm{RC}$ or randomization. The secondary endpoint was OS, which was defined as the interval between $\mathrm{RC}$ or randomization and death from $\mathrm{MIBC}$ or any other cause.

\section{Study quality assessments}

In individual studies, the risk of bias was assessed using tools recommended in recent meta-analysis guidelines that assessed aspects of RCT design and implementation [20,21]. The risk of bias assessment included examination of the use of random sequence generation, allocation concealment, blinding of participants and researchers, blinding of outcome assessment, incomplete outcome data, and selective reporting.

We evaluated the certainty of comparisons using Grading of Recommendations, Assessments, Developments, and Evaluation (GRADE) system that provides a systematic approach to evaluation of the quality of evidence and strength of recommendations [21]. GRADE consisted of methodology, precision, consistency, directness, and risk of publication bias. Based on these criteria, we assessed 
evidence of meta-analysis by classifying the quality of evidence on four levels of high, moderate, low, and very low.

\section{Statistical analysis}

The effects of ACH on outcomes were measured using HRs. Log HR values were obtained directly from the trials reporting $\mathrm{HR}$ point estimates and CIs, and the standard errors of log-HRs were calculated using the published CIs [22]. Some studies reported Kaplan-Meier log-rank or Wilcoxon p-values; however, they did not include HRs or 95\% CIs, or both. In these cases, we estimated HRs and 95\% CIs using p-values, numbers of total events, and numbers that were randomized to each arm [23]. Estimates for the included studies were then combined using a random effects model with inverse variance [24]. Pooled HRs with 95\% CIs indicated the effects of ACH on OS and PFS. Chisquare heterogeneity tests were used to test for statistical heterogeneity between trials. The $\mathrm{I}^{2}$ statistic was calculated to measure discrepancies between clinical trials [25]. A Cochran Q statistic p-value $<0.05$ or an $\mathrm{I}^{2}$ statistic $>50 \%$ were used to indicate the presence of statistically significant heterogeneity between RCTs [21]. We assessed the stability of results when each included study was sequentially excluded for sensitivity analysis. The Egger linear regression and funnel plots were used for evaluation of publication bias. Symmetry reversal funnel diagrams did not show significant publication bias; If the bias exists, the inverted funnel plots should appear distorted and asymmetrical. Additionally, significant statistical publication bias was suspected when $\mathrm{p}$ value was less than 0.05 on Egger's test.

We used Review Manager v.5.1 (2008; Nordic Cochrane Center, Cochrane Collaboration, Copenhagen, Denmark) for performing meta-analysis. All p-values were two-sided; and except for the test of discrepancy, p-value $<0.05$ was considered statistically significant.

\section{RESULTS}

\section{Systematic review process}

The results for PRISMA flow diagram are presented in Fig. 1. The initial database search found 1,575 articles; among them, 1,315 remained after duplicates were removed. We then examined the titles and abstracts; through this review, 1,273 articles were excluded. After that, analysis of fulltext articles was performed based on the inclusion criteria. Four RCTs with a total of 490 patients were included in this study $[14,15,18,26]$.

The information for the included studies is presented in Tables 1 and 2 [14,15,18,26]. All included trials were prospective RCTs. One study was performed in Europe [15], two studies were performed in the United States [14,26], and one study was a multicenter RCT that included patients from Europe and Canada [18]. Four trials enrolled patients with locally advanced MIBC (pT3-4 and/or pN+ and M0).

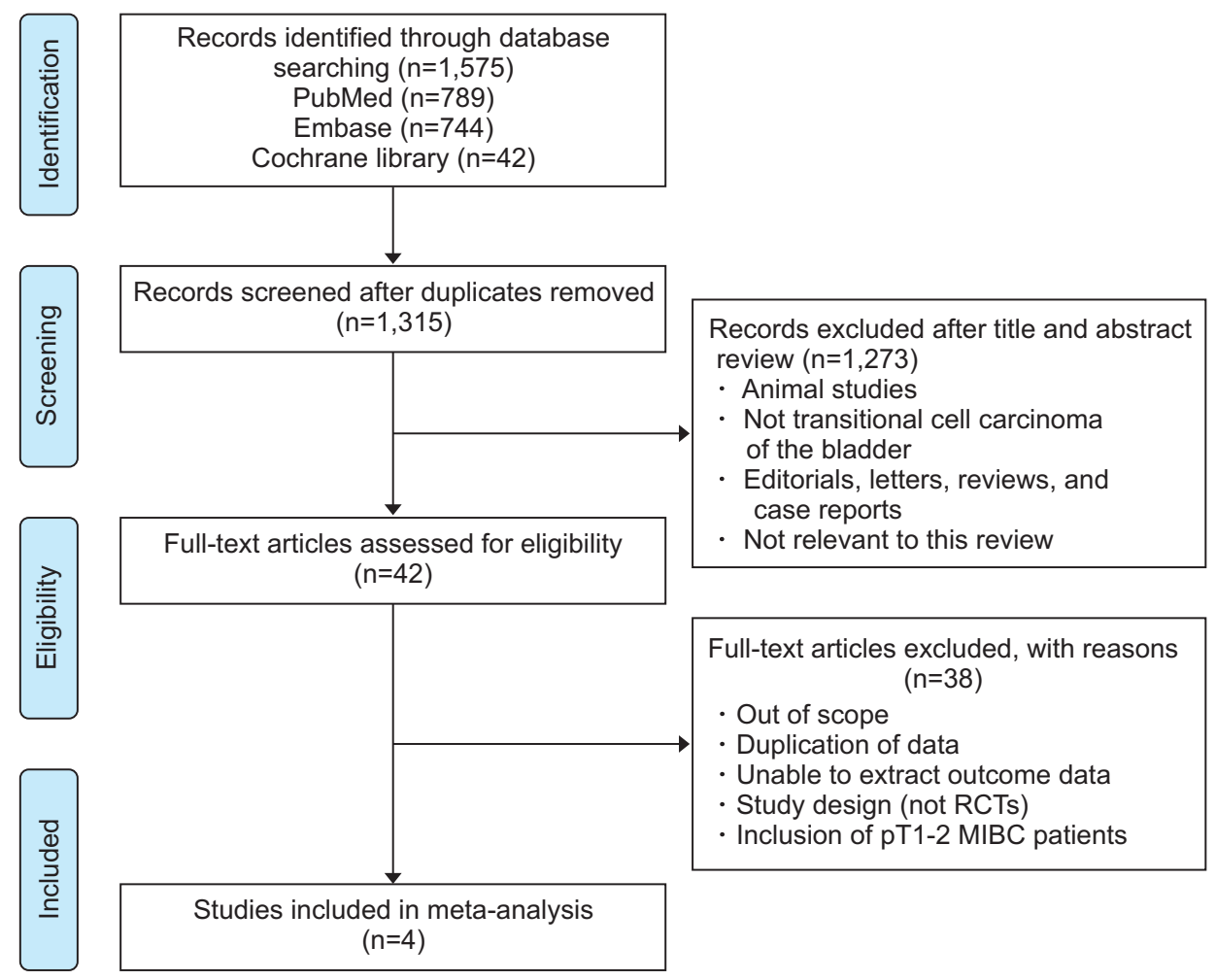

Fig. 1. Preferred reporting items for systematic reviews and meta-analysis flowchart. RCT, randomized controlled trial; MIBC, muscle-invasive bladder cancer. 


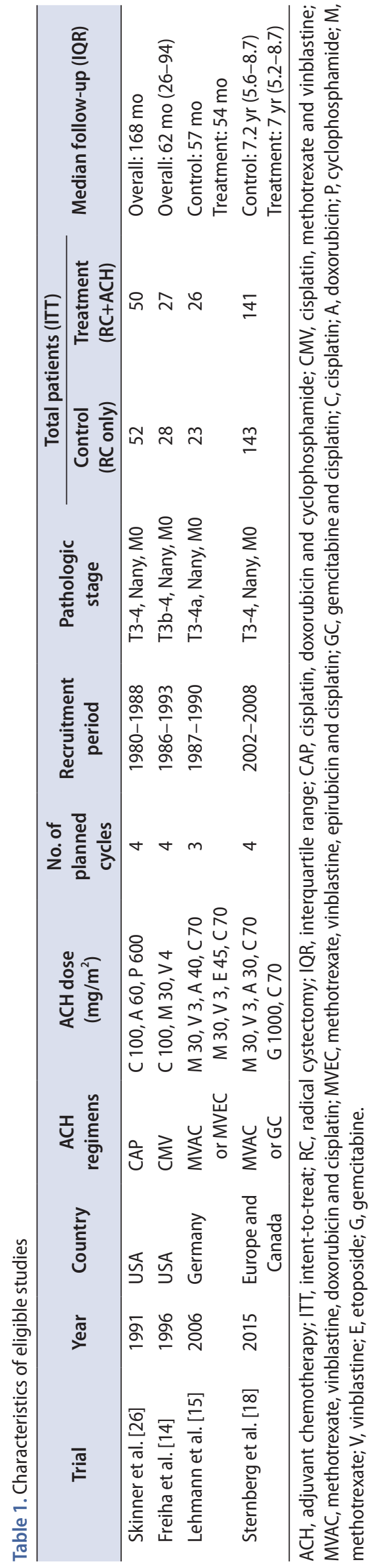

The chemotherapy regimens used varied between studies. Three or four cycles of $\mathrm{ACH}$ were used in most of the trials.

\section{Primary endpoint: PFS}

Meta-analysis of the included trials revealed an overall HR of 0.48 for PFS for ACH ( $p<0.00001 ; 95 \%$ CI, 0.39-0.60; Fig. $2 \mathrm{~A})$. Results indicated that the among-study heterogeneity was statistically significant (Cochran $Q$ statistic, $p=0.65 ; I^{2}$ statistic, 0\%). The absolute increases in PFS for all trials was $17 \%$, respectively (i.e, equivalent to numbers needed to treat of 5.9 , respectively).

\section{Secondary endpoint: overall survival}

Analysis of the random-effects model revealed that pooled HR across all studies was $0.63(\mathrm{p}=0.0009$; $95 \%$ CI, 0.48 0.83; Fig. 2B); among-study heterogeneity was not statistically significant (Cochran Q statistic, $\mathrm{p}=0.28 ; \mathrm{I}^{2}$ statistic, $22 \%$ ). The absolute increase in OS for all trials was 10\%, respectively (i.e., equivalent to numbers needed to treat of 10 , respectively).

\section{Sensitivity analyses}

Sensitivity analysis was performed using sequential exclusion of studies to evaluate the effect of each study on overall meta-analysis results. Trial by Sternberg et al. [18] had the greatest negative effects on both PFS and OS HRs. Study by Lehmann et al. [15] had the largest positive effects on PFS, and Skinner et al. [26] showed the largest positive effects on OS HRs, respectively. Exclusion of any one study did not result in any statistically significant changes in the results. Results were statistically reliable.

\section{Publication bias}

For both PFS and OS, significant publication bias was not observed in statistical tests. Funnel plots for publication bias for PFS and OS showed a certain degree of symmetry (Fig. 3). Furthermore, the Begg's tests also demonstrated that there was no statistical evidence of publication bias in this meta-analysis of PFS ( $\mathrm{p}=0.214)$ and $\mathrm{OS}(\mathrm{p}=0.717)$.

\section{Quality assessment and qualitative risk of bias}

Results for the risk of bias assessment and graph are shown in Figs 4. and 5. There were two main sources of bias. The first source was unblinded study design, which would cause bias in the results towards $\mathrm{ACH}$. The second source was early trial termination. The reasons for early discontinuation was showing $\mathrm{ACH}$ effect to be greater [15]. Early discontinuation of a trial was included as other bias.

The results of GRADE quality assessment of direct evidence of each comparison are shown in Table 3. Certainty 
Table 2. Treatment characteristics of included studies

\begin{tabular}{|c|c|c|c|c|c|c|c|}
\hline Trial & $\begin{array}{l}\text { Median age, } \\
\text { range }(y)\end{array}$ & $\begin{array}{l}\text { Interval between } \\
\mathrm{RC} \text { and } \mathrm{ACH}\end{array}$ & $\begin{array}{l}\text { Number of } \\
\text { surgeon }\end{array}$ & $\begin{array}{l}\text { Surgical } \\
\text { type of RC }\end{array}$ & $\begin{array}{l}\mathrm{ACH} \\
\text { regimens }\end{array}$ & $\begin{array}{l}\text { ACH dose } \\
\left(\mathrm{mg} / \mathrm{m}^{2}\right)\end{array}$ & $\begin{array}{c}\text { No. of } \\
\text { planned } \\
\text { cycles }\end{array}$ \\
\hline Skinner et al. [26] & $\begin{array}{l}\text { Control: } 62,30-73 \\
\text { ACH: } 61,22-75\end{array}$ & $6 \mathrm{wk}$ & 3 & Open & CAP & C 100, A 60, P 600 & 4 \\
\hline Freiha et al. [14] & $\begin{array}{l}\text { Control: } 64 \text { (mean), 49-78 } \\
\text { ACH: } 59 \text { (mean), 40-76 }\end{array}$ & 6 wk & NA & NA & CMV & $\mathrm{C} 100, \mathrm{M} 30, \mathrm{~V} 4$ & 4 \\
\hline Lehmann et al. [15] & $\begin{array}{l}\text { Control: } 62.7 \\
\mathrm{ACH}: 58.8\end{array}$ & NA & NA & NA & $\begin{array}{l}\text { MVAC } \\
\text { or MVEC }\end{array}$ & $\begin{array}{l}M 30, V 3, A 40, C 70 \\
M 30, V 3, E 45, C 70\end{array}$ & 3 \\
\hline Sternberg et al. [18] & $\begin{array}{l}\text { Control: 61, 37-76 } \\
\text { ACH: 61, 35-82 }\end{array}$ & $90 d$ & NA & NA & $\begin{array}{l}\text { MVAC } \\
\text { or GC }\end{array}$ & $\begin{array}{l}\text { M 30, V 3, A 30, C } 70 \\
\text { G 1000, C } 70\end{array}$ & 4 \\
\hline
\end{tabular}

$\mathrm{RC}$, radical cystectomy; $\mathrm{ACH}$, adjuvant chemotherapy; NA, not available; CAP, cisplatin, doxorubicin and cyclophosphamide; CMV, cisplatin, methotrexate and vinblastine; MVAC, methotrexate, vinblastine, doxorubicin and cisplatin; MVEC, methotrexate, vinblastine, epirubicin and cisplatin; GC, gemcitabine and cisplatin; C, cisplatin; A, doxorubicin; P, cyclophosphamide; M, methotrexate; V, vinblastine; E, etoposide; G, gemcitabine.

A

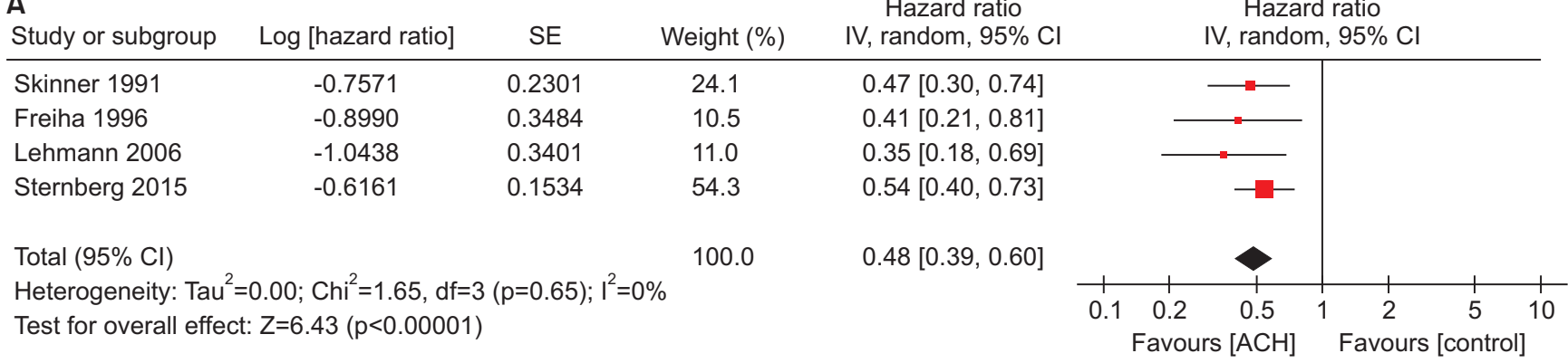

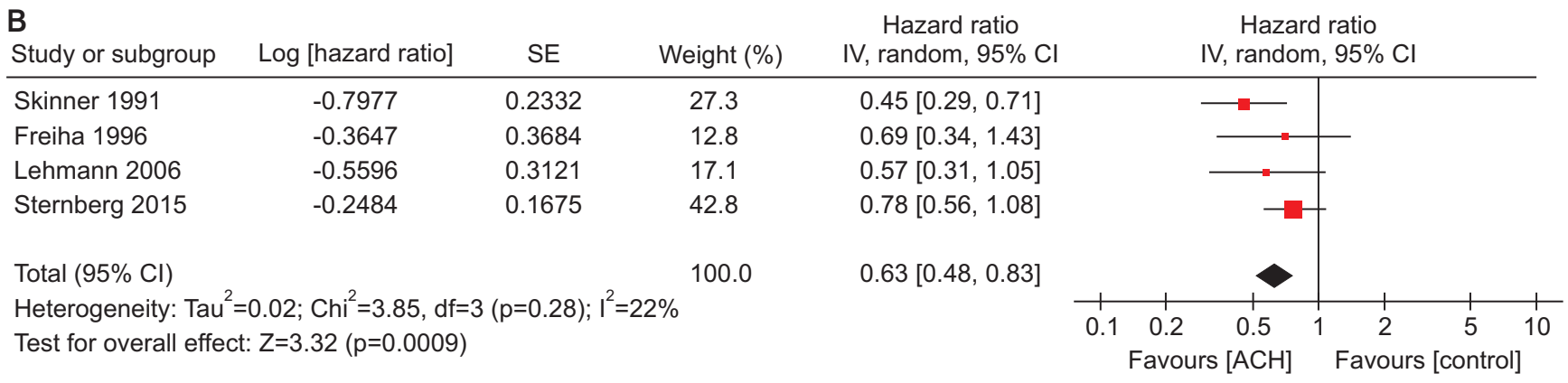

Fig. 2. (A) Forest plots of PFS in locally advanced MIBC (pT3-4 and/or pN+ and MO), (B) forest plots of OS in locally advanced MIBC (pT3-4 and/or pN+ and M0). PFS, progression-free survival; MIBC, muscle-invasive bladder cancer; OS, overall survival; SE, standard error; $\mathrm{Cl}$, confidence interval; $\mathrm{df}$, degrees of freedom; $\mathrm{ACH}$, adjuvant chemotherapy.

was moderate in all of the two comparisons.

\section{DISCUSSION}

$\mathrm{ACH}$ has been used to manage MIBC, to eradicate micrometastatic lesions, and to enhance postoperative survival outcomes [27-29]. The main advantage of $\mathrm{ACH}$ after RC is that after assessing pathologic primary tumor and regional lymph node categories, clinicians can choose patients with highest risk for recurrence who are most likely to benefit from ACH without delay in definitive treatment. Several RCTs have been performed to investigate the effects of ACH in patients with MIBC [14,26,30-34]. Meta- analyses have found statistically significant evidence for the benefits of ACH use for OS and PFS in these patients $[6,8,9]$. However, these studies had limitations, such as small sample sizes, early patient entry interruption, analysis and terminology confusion, and questionable interpretation of results [35,36]. We focused on trials regarding the effect of $\mathrm{ACH}$ on locally advanced MIBC patients only, and conducted a meta-analysis of these papers through systematic review.

We found a positive benefit of $\mathrm{ACH}$ on PFS and OS compared to no $\mathrm{ACH}$, following $\mathrm{RC}$ in patients with locally advanced MIBC. We reported a 52\% relative risk reduction in progression and a $48 \%$ reduction in the risk of death. Leow et al. [9] used a meta-analysis to examine the effects of 
A

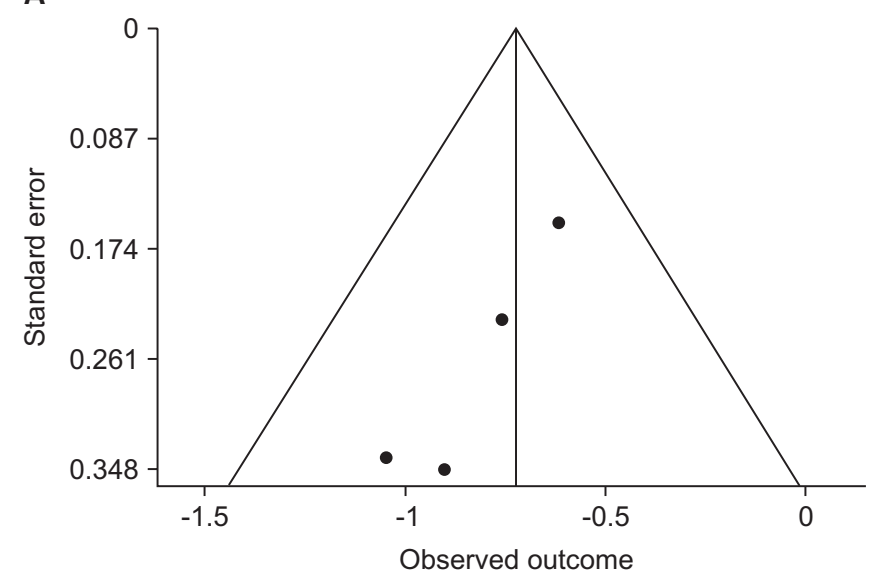

B

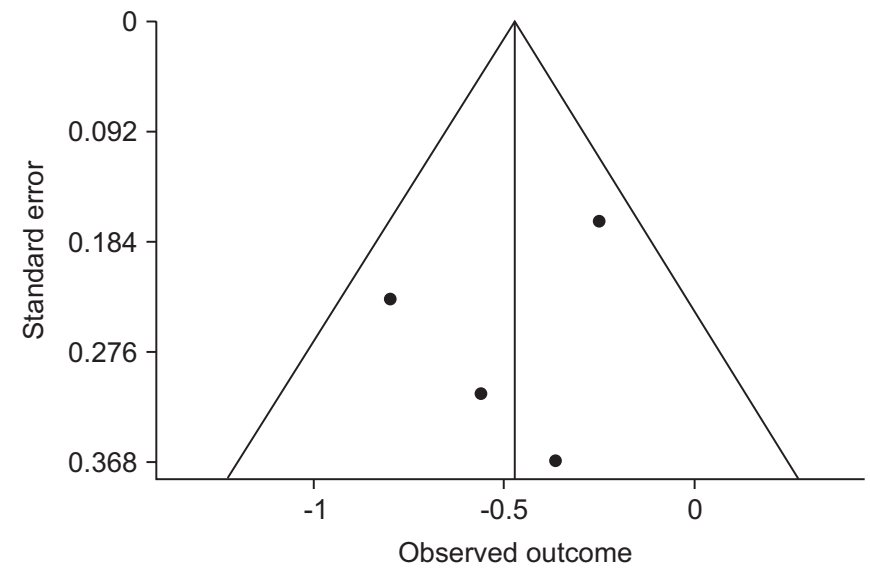

Fig. 3. Funnel plots for publication bias. (A) Progression-free survival. (B) Overall survival.

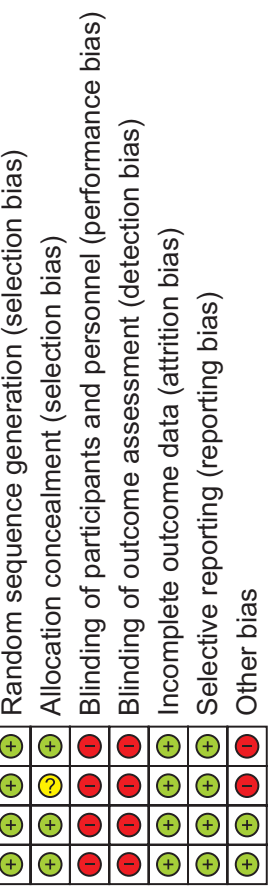

Fig. 4. Risk of bias assessment. Green plus indicates low risk of bias; yellow question mark indicates unclear risk of bias; red minus indicates high risk of bias.

adjuvant cisplatin-based chemotherapy after $\mathrm{RC}$ in patients with MIBC. They found that ACH improves disease-free survival and OS rates by $34 \%$ and $22 \%$, respectively. Vale et al. [8] also found that ACH improves disease-free survival and OS rates of patients with MIBC by $32 \%$ and $25 \%$, respectively. After comparing these results with ours, we found that our analysis showed ACH may be more effective in locally advanced MIBC patients than in MIBC patients. This study supports the possibility that beneficial effects of $\mathrm{ACH}$ may be greater for locally advanced MIBC patients.

Another difference between previous meta-analyses $[6,8,9]$ and ours was the exclusion of conference abstracts. The two conference abstracts included in previous meta-analyses have not been fully published [31,32]. Results published in abstracts were often very different from the results published in full-length articles; abstracts were generally not subjected to the strict peer review process typically required for journal articles. Therefore, unconfirmed bias may have affected the results of systematic reviews, including abstracts [37]. The Agency for Healthcare Research and Quality does not recommend the use of conference and meeting abstracts for evaluating selective outcome reporting and selective analysis reporting, given the variability in degree of agreement between conference abstracts and their subsequent full-text publications [38].

Our study did have some limitations. Since access to individual patient data was not possible, additional survival analyses could not be performed for similar covariates. There were also some between-trial differences in definitions of the endpoints (PFS and OS). Two trials defined it as time from $\mathrm{RC}$ until the earliest occurrence of relapse or death from any cause $[14,26]$. Other trials defined it as the time from randomization [15,18]. Another important limitation in this study was that the defects from earlier trials could have affected the outcomes. Two trials were discontinued early due to beneficial interim results [14,15], which could have affected the results of a later meta-analysis [8]. In two trials, approximately one-quarter of the patients randomized to treatment group did not receive chemotherapy [15,26]. Lehmann et al. [15] also had serious methodological fault. Most of control group patients with disease progression did not receive chemotherapy for recurrence; one-third of treatment group patients also did not receive chemotherapy [9]. The most significant effect of these design flaws was likely dilution of the positive and negative effects of 


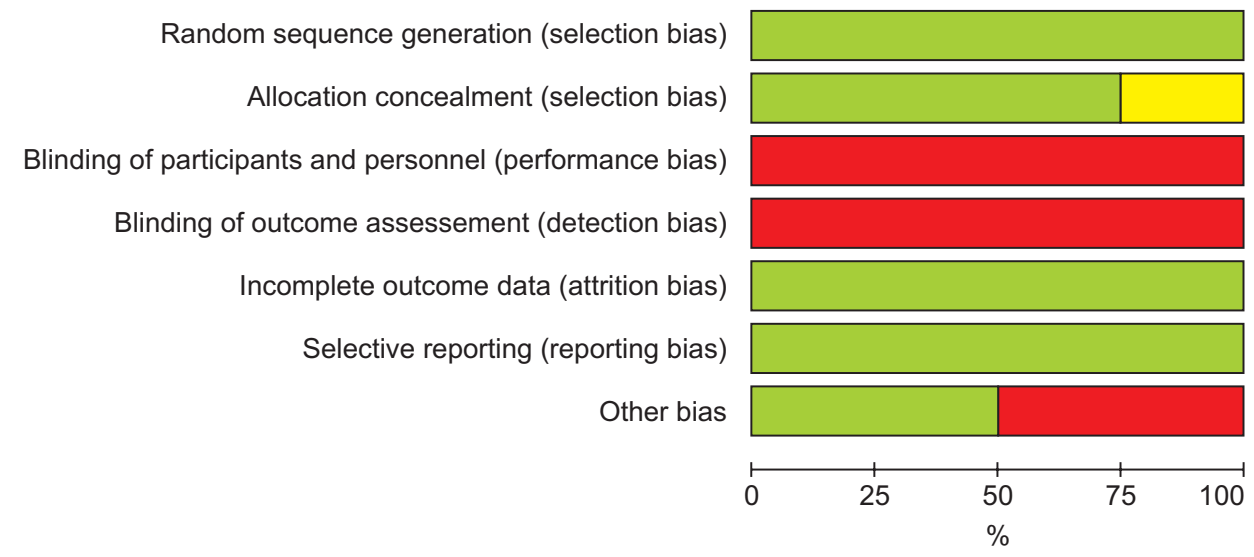

Low risk of bias

Unclear risk of bias

High risk of bias

Fig. 5. Risk of bias graph.

chemotherapy.

Level 1 evidence supports the use of NAC to improve OS of patients with MIBC, but adoption rates remain low [39]. Cowan et al. [10] used a survey to determine factors related to NAC use, define reasons for low utilization, and the current rate of NAC use among urologic oncologists. They found NAC adoption rates between $30 \%$ and $57 \%$, although the urologic oncologists discussed NAC with $>90 \%$ of their patients and medical oncologists recommended NAC. Among major concerns regarding the use of NAC, age and comorbidities accounted for the greatest proportion, followed by delay in surgery, marginal benefit, prolonged diagnosis and referral, better adjuvant therapy choices, too toxic for surgical patient, and risk of surgical complications. The use of NAC can have negative effects on assessing response to therapy, due to discrepancies between interpretation of clinical and pathologic stages; patient is then more likely to receive unnecessary treatment. Despite the availability of level 1 evidence, use of NAC and $\mathrm{ACH}$ for bladder cancer (BCa) remains low [9,40,41]. Expectedly, chemotherapy use is even lower for upper tract urothelial carcinoma (UTUC), due to the absence of corresponding strong evidence [42]. Therefore, the outcome of ongoing Phase II/III clinical trial was enthusiastically anticipated, and perioperative chemotherapy versus surveillance in upper tract urothelial cancer (POUT) trial recently published the results [43]. POUT trial addresses whether ACH improves survival for patients with locally advanced or node-positive UTUC (pT2-T4, N0-3, M0). POUT trial provides a high-level of evidence for the added value of $\mathrm{ACH}$ in patients with locally advanced or node-positive UTUC. However, this trial was prematurely discontinued by the safety monitoring committee, due to significant improvement in disease-free survival [43]. In addition, this trial may be limited due to inadequate stratification of local or locoregional disease [42].

The National Comprehensive Cancer Network (NCCN) guidelines suggest that $\mathrm{ACH}$ may be given to patients with high-risk pathology who did not receive NAC (category $2 \mathrm{~A}$ recommendation) [44]. That is, based on relatively low-level evidence, there is unified NCCN agreement that intervention is appropriate. In patients with pT3-4 and/or N+ M0 disease, 5-year survival rate after $\mathrm{RC}$ is only $30 \%$ at most. As a result, $\mathrm{ACH}$ was administered to high-risk patients to delay relapse and prolong survival [45]. This approach of administering chemotherapy after local treatment increases survival in patients with many different solid tumors [46,47]. It also prevents overtreatment for patients who are suspected of having a reasonable outcome with only surgery, that is, those with tumor localized to the bladder [45]. A more sophisticated analysis of molecular prognostic and predictive markers by available sufficient tissue is also an advantage. If micrometastases are present, a clinician can treat them when they are at a low volume rather than waiting for an overt metastatic disease [45]. ACH also has disadvantages of delayed treatment for micrometastatic disease, and results in limitation of administration of chemotherapy due to postoperative morbidity [48]. There is no accurate answer to the question of whether ACH is less effective than NAC, as they both have advantages and disadvantages. No study directly compares the effects of both. Yin et al. [49] found that NAC is associated with a survival benefit (absolute increase of $8 \% \mathrm{OS}$ ), which is equivalent to a number needed to treat of 12.5. We calculated the absolute increases in OS by ACH in MIBC patients using a study by Leow et al. [9], and found a $4 \%$ increase in results (i.e., numbers needed to treat, 25). Our study found that the absolute increases in OS for use of ACH in patients with locally advanced MIBC was $10 \%$, respectively (i.e., numbers needed to treat, 10 ). 


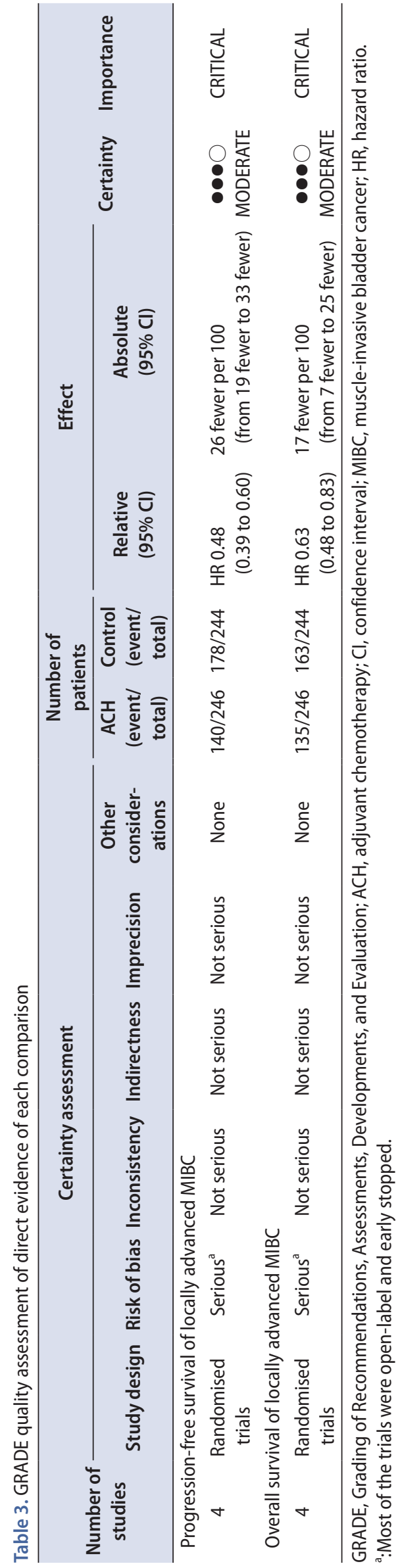

Although ACH, when used for all MIBC patients, seems to have a marginal benefit ( $4 \%$ increase), overtreatment is a concern (number needed to treat, 25). However, if ACH were offered only to patients with locally advanced MIBC, the number needed to treat using $\mathrm{ACH}$ may be lower than that of NAC (10 versus 12.5). Therefore, a larger collaborative international and well-designed RCT will be needed to determine the true value of postoperative chemotherapy. The effects of $\mathrm{ACH}$ and NAC in patients with MIBC or locally advanced MIBC should also be compared.

Over the past 30 years, there has been no significant progress in the treatment of metastatic $\mathrm{BCa}$, and chemotherapy is still the standard of care [50]. However, advances in the perception of pathophysiology provided by comprehensive genomic profiling of $\mathrm{BCa}$ may greatly improve the outcomes of this malignancy [51]. The relevance of PD-1 blockade in urothelial cancer has been recently confirmed by a phase I study to evaluate a human monoclonal antibody directed against PD-L1 (MPDL3280A), including 67 patients with metastatic BCa [52]. This trial verified the checkpoint PD-1 pathway as a promising therapeutic target in $\mathrm{BCa}$ [53]. Rapidly evolving knowledge of urothelial carcinoma pathophysiology and identified fundamental molecular alterations will provide the basis for new therapies, and apply new therapeutic effects through a well-designed trial.

\section{CONCLUSIONS}

Our meta-analysis of four RCTs found that ACH may provide benefits for PFS and OS in patients with locally advanced $\mathrm{MIBC}$ who received $\mathrm{ACH}$ after $\mathrm{RC}$, compared to those who underwent surgery alone. Our results, compared to previously reported meta-analysis, suggest that beneficial effects of $\mathrm{ACH}$ may be greater in patients with locally advanced MIBC patients than in those with MIBC.

\section{CONFLICTS OF INTEREST}

The authors have nothing to disclose.

\section{REFERENCES}

1. Stein JP, Lieskovsky G, Cote R, Groshen S, Feng AC, Boyd S, et al. Radical cystectomy in the treatment of invasive bladder cancer: long-term results in 1,054 patients. J Clin Oncol 2001;19:666-75.

2. Erlich A, Zlotta AR. Treatment of bladder cancer in the elderly. Investig Clin Urol 2016;57 Suppl 1:S26-35. 
3. Quek ML, Stein JP, Clark PE, Daneshmand S, Miranda G, Cai J, et al. Natural history of surgically treated bladder carcinoma with extravesical tumor extension. Cancer 2003;98:955-61.

4. Shariat SF, Karakiewicz PI, Palapattu GS, Lotan Y, Rogers CG, Amiel GE, et al. Outcomes of radical cystectomy for transitional cell carcinoma of the bladder: a contemporary series from the Bladder Cancer Research Consortium. J Urol 2006;176:2414-22; discussion 2422.

5. Alfred Witjes J, Lebret T, Compérat EM, Cowan NC, De Santis M, Bruins HM, et al. Updated 2016 EAU guidelines on muscleinvasive and metastatic bladder cancer. Eur Urol 2017;71:46275.

6. Kim HS, Jeong CW, Kwak C, Kim HH, Ku JH. Adjuvant chemotherapy for muscle-invasive bladder cancer: a systematic review and network meta-analysis of randomized clinical trials. Oncotarget 2017;8:81204-14.

7. Sternberg CN, Bellmunt J, Sonpavde G, Siefker-Radtke AO, Stadler WM, Bajorin DF, et al. ICUD-EAU International Consultation on Bladder Cancer 2012: chemotherapy for urothelial carcinoma-neoadjuvant and adjuvant settings. Eur Urol 2013;63:58-66.

8. Advanced Bladder Cancer (ABC) Meta-analysis Collaboration. Adjuvant chemotherapy in invasive bladder cancer: a systematic review and meta-analysis of individual patient data Advanced Bladder Cancer (ABC) meta-analysis collaboration. Eur Urol 2005;48:189-99; discussion 199-201.

9. Leow JJ, Martin-Doyle W, Rajagopal PS, Patel CG, Anderson EM, Rothman AT, et al. Adjuvant chemotherapy for invasive bladder cancer: a 2013 updated systematic review and metaanalysis of randomized trials. Eur Urol 2014;66:42-54.

10. Cowan NG, Chen Y, Downs TM, Bochner BH, Apolo AB, Porter MP, et al. Neoadjuvant chemotherapy use in bladder cancer: a survey of current practice and opinions. Adv Urol 2014;2014:746298.

11. Kim SH, Seo HK, Shin HC, Chang SJ, Yun S, Joo J, et al. Trends in the use of chemotherapy before and after radical cystectomy in patients with muscle-invasive bladder cancer in Korea. J Korean Med Sci 2015;30:1150-6.

12. Muss HB, Biganzoli L, Sargent DJ, Aapro M. Adjuvant therapy in the elderly: making the right decision. J Clin Oncol 2007;25:1870-5.

13. Cognetti F, Ruggeri EM, Felici A, Gallucci M, Muto G, Pollera $\mathrm{CF}$, et al. Adjuvant chemotherapy with cisplatin and gemcitabine versus chemotherapy at relapse in patients with muscle-invasive bladder cancer submitted to radical cystectomy: an Italian, multicenter, randomized phase III trial. Ann Oncol 2012;23:695-700.

14. Freiha F, Reese J, Torti FM. A randomized trial of radical cystectomy versus radical cystectomy plus cisplatin, vinblastine and methotrexate chemotherapy for muscle invasive bladder cancer. J Urol 1996;155:495-9; discussion 499-500.

15. Lehmann J, Franzaring L, Thüroff J, Wellek S, Stöckle M. Complete long-term survival data from a trial of adjuvant chemotherapy vs control after radical cystectomy for locally advanced bladder cancer. BJU int 2006;97:42-7.

16. Lehmann J, Retz M, Wiemers C, Beck J, Thüroff J, Weining C, et al. Adjuvant cisplatin plus methotrexate versus methotrexate, vinblastine, epirubicin, and cisplatin in locally advanced bladder cancer: results of a randomized, multicenter, phase III trial (AUO-AB 05/95). J Clin Oncol 2005;23:4963-74.

17. Stadler WM, Lerner SP, Groshen S, Stein JP, Shi SR, Raghavan $\mathrm{D}$, et al. Phase III study of molecularly targeted adjuvant therapy in locally advanced urothelial cancer of the bladder based on p53 status. J Clin Oncol 2011;29:3443-9.

18. Sternberg CN, Skoneczna I, Kerst JM, Albers P, Fossa SD, Agerbaek M, et al. Immediate versus deferred chemotherapy after radical cystectomy in patients with pT3-pT4 or N+ M0 urothelial carcinoma of the bladder (EORTC 30994): an intergroup, open-label, randomised phase 3 trial. Lancet Oncol 2015;16:76-86.

19. Moher D, Shamseer L, Clarke M, Ghersi D, Liberati A, Petticrew M, et al. Preferred reporting items for systematic review and meta-analysis protocols (PRISMA-P) 2015 statement. Syst Rev 2015;4:1.

20. Liberati A, Altman DG, Tetzlaff J, Mulrow C, Gøtzsche PC, Ioannidis JP, et al. The PRISMA statement for reporting systematic reviews and meta-analyses of studies that evaluate health care interventions: explanation and elaboration. PLoS Med 2009;6:e1000100.

21. Higgins JP, Altman DG, Gøtzsche PC, Jüni P, Moher D, Oxman AD, et al. The Cochrane Collaboration's tool for assessing risk of bias in randomised trials. BMJ 2011;343:d5928.

22. Parmar MK, Torri V, Stewart L. Extracting summary statistics to perform meta-analyses of the published literature for survival endpoints. Stat Med 1998;17:2815-34.

23. Tierney JF, Stewart LA, Ghersi D, Burdett S, Sydes MR. Practical methods for incorporating summary time-to-event data into meta-analysis. Trials 2007;8:16.

24. Berkey CS, Hoaglin DC, Mosteller F, Colditz GA. A random-effects regression model for meta-analysis. Stat Med 1995;14:395-411.

25. Higgins JP, Thompson SG, Deeks JJ, Altman DG. Measuring inconsistency in meta-analyses. BMJ 2003;327:557-60.

26. Skinner DG, Daniels JR, Russell CA, Lieskovsky G, Boyd SD, Nichols $\mathrm{P}$, et al. The role of adjuvant chemotherapy following cystectomy for invasive bladder cancer: a prospective comparative trial. J Urol 1991;145:459-64; discussion 464-7.

27. Furuta A, Suzuki Y, Kimura S, Asano K, Egawa S, Yoshimura N. 
Noradrenergic mechanisms controlling urethral smooth and striated muscle function in urethral continence reflex in rats. Low Urin Tract Symptoms 2015;7:155-61.

28. Park J, Park S, Song C, Doo C, Cho YM, Ahn H, et al. Effectiveness of adjuvant chemotherapy in transitional cell carcinoma of the urinary bladder with lymph node involvement and/or lymphovascular invasion treated by radical cystectomy. Urology 2007;70:257-62.

29. Yelfimov DA, Frank I, Boorjian SA, Thapa P, Cheville JC, Tollefson MK. Adjuvant chemotherapy is associated with decreased mortality after radical cystectomy for locally advanced bladder cancer. World J Urol 2014;32:1463-8.

30. Bono AV, Benvenuti C, Reali L, Pozzi E, Gibba A, CoscianiCunico S, et al. Adjuvant chemotherapy in advanced bladder cancer. Italian Uro-Oncologic Cooperative Group. Prog Clin Biol Res 1989;303:533-40.

31. Otto T, Börgemann C, Krege S. Adjuvant chemotherapy in locally advanced bladder cancer (PT3/PN1-2,M0)-a phase III study. Eur Urol 2001;39:147.

32. Paz-Ares LG, Solsona E, Esteban E, Saez A, Gonzalez-Larriba J, Anton A, et al. Randomized phase III trial comparing adjuvant paclitaxel/gemcitabine/cisplatin (PGC) to observation in patients with resected invasive bladder cancer: results of the Spanish Oncology Genitourinary Group (SOGUG) 99/01 study. J Clin Oncol 2010;28(18 Suppl):951S.

33. Stöckle M, Meyenburg W, Wellek S, Voges G, Gertenbach U, Thüroff JW, et al. Advanced bladder cancer (stages pT3b, pT4a, $\mathrm{pN} 1$ and $\mathrm{pN} 2$ ): improved survival after radical cystectomy and 3 adjuvant cycles of chemotherapy. Results of a controlled prospective study. J Urol 1992;148:302-6; discussion 306-7.

34. Studer UE, Bacchi M, Biedermann C, Jaeger P, Kraft R, Mazzucchelli L, et al. Adjuvant cisplatin chemotherapy following cystectomy for bladder cancer: results of a prospective randomized trial. J Urol 1994;152:81-4.

35. Boccardo F, Palmeri L. Adjuvant chemotherapy of bladder cancer. Ann Oncol 2006;17 Suppl 5:v129-32.

36. Sylvester R, Sternberg C. The role of adjuvant combination chemotherapy after cystectomy in locally advanced bladder cancer: what we do not know and why. Ann Oncol 2000;11:851-6.

37. Hoag CC, Elterman DS, Macneily AE. Abstracts presented at the American Urological Association Annual Meeting: determinants of subsequent peer reviewed publication. J Urol 2006;176:2624-9.

38. Balshem H, Stevens A, Ansari M, Norris S, Kansagara D, Shamliyan T, et al. Finding grey literature evidence and assessing for outcome and analysis reporting biases when comparing medical interventions: AHRQ and the effective health care program [Internet]. Rockville: Agency for Healthcare Research and Quality (US); 2013 Nov 18 [cited 2018 Aug 2]. Available from: https://www.ncbi.nlm.nih.gov/books/NBK174882/

39. David KA, Milowsky MI, Ritchey J, Carroll PR, Nanus DM. Low incidence of perioperative chemotherapy for stage III bladder cancer 1998 to 2003: a report from the National Cancer Data Base. J Urol 2007;178:451-4.

40. Advanced Bladder Cancer (ABC) Meta-analysis Collaboration. Neoadjuvant chemotherapy in invasive bladder cancer: update of a systematic review and meta-analysis of individual patient data advanced bladder cancer (ABC) meta-analysis collaboration. Eur Urol 2005;48:202-5; discussion 205-6.

41. Reardon ZD, Patel SG, Zaid HB, Stimson CJ, Resnick MJ, Keegan KA, et al. Trends in the use of perioperative chemotherapy for localized and locally advanced muscle-invasive bladder cancer: a sign of changing tides. Eur Urol 2015;67:16570.

42. Leow JJ, Martin-Doyle W, Fay AP, Choueiri TK, Chang SL, Bellmunt J. A systematic review and meta-analysis of adjuvant and neoadjuvant chemotherapy for upper tract urothelial carcinoma. Eur Urol 2014;66:529-41.

43. Birtle AJ, Chester JD, Jones RJ, Johnson M, Hill M, Bryan RT, et al. Results of POUT: a phase III randomised trial of perioperative chemotherapy versus surveillance in upper tract urothelial cancer (UTUC). J Clin Oncol 2018;36(6 Suppl):407.

44. Spiess PE, Agarwal N, Bangs R, Boorjian SA, Buyyounouski MK, Clark PE, et al. Bladder cancer, version 5.2017, NCCN Clinical Practice Guidelines in Oncology. J Natl Compr Canc Netw 2017;15:1240-67.

45. Calabrò F, Sternberg CN. Neoadjuvant and adjuvant chemotherapy in muscle-invasive bladder cancer. Eur Urol 2009;55:348-58.

46. Sternberg CN. Neo-adjuvant and adjuvant chemotherapy of bladder cancer: is there a role? Ann Oncol 2002;13 Suppl 4:273-9.

47. de Braud F, Maffezzini M, Vitale V, Bruzzi P, Gatta G, Hendry WF, et al. Bladder cancer. Crit Rev Oncol Hematol 2002;41:89106.

48. Sternberg CN, Donat SM, Bellmunt J, Millikan RE, Stadler W, De Mulder P, et al. Chemotherapy for bladder cancer: treatment guidelines for neoadjuvant chemotherapy, bladder preservation, adjuvant chemotherapy, and metastatic cancer. Urology 2007;69(1 Suppl):62-79.

49. Yin M, Joshi M, Meijer RP, Glantz M, Holder S, Harvey HA, et al. Neoadjuvant chemotherapy for muscle-invasive bladder cancer: a systematic review and two-step meta-analysis. Oncologist 2016;21:708-15.

50. Powles T, Eder JP, Fine GD, Braiteh FS, Loriot Y, Cruz C, et al. MPDL3280A (anti-PD-L1) treatment leads to clinical activity in metastatic bladder cancer. Nature 2014;515:558-62. 
51. Cancer Genome Atlas Research Network. Comprehensive molecular characterization of urothelial bladder carcinoma. Nature 2014;507:315-22.

52. Powles T, Vogelzang NJ, Fine GD, Eder JP, Braiteh FS, Loriot Y, et al. Inhibition of PD-L1 by MPDL3280A and clinical activity in pts with metastatic urothelial bladder cancer (UBC). J Clin Oncol 2014;32(15 Suppl):5011.

53. Carneiro BA, Meeks JJ, Kuzel TM, Scaranti M, Abdulkadir SA, Giles FJ. Emerging therapeutic targets in bladder cancer. Cancer Treat Rev 2015;41:170-8. 